\title{
THE CULTIVATION OF VICTORIA AMAZONICA SOWERBY IN NORTHERN LATITUDES
}

\section{Pat Clifford ${ }^{1}$}

Victoria amazonica Sowerby has been cultivated in Britain since the 1830 s. In this paper the cultivation of this species at the Royal Botanic Garden Edinburgh is outlined with reference to its native environment, including propagation, planting out, general maintenance, flowering and pollination.

\section{INTRODUCTION}

Victoria amazonica Sowerby is in the water lily family Nymphaeaceae. It is endemic to the Amazon basin in South America, primarily in Guyana, Brazil and Bolivia. The largest of all water lilies, the Victoria water lily is found in the warm, still waters of the swamps and ox bow lakes of the Amazon River. This paper describes its history and cultivation in Britain and at the Royal Botanic Garden Edinburgh (RBGE) in particular.

Victoria amazonica was first discovered in 1801 by the Bohemian botanist Tadeas Haenke in Bolivia (Anderson, 1965). However, it was not until 1837 that the English botanist John Lindley established the genus Victoria and described the species Victoria regia in honour of Queen Victoria (Lindley, 1837).

Soon after Lindley's description, attempts began to cultivate the plant in England. However, it was not until 1849 that it was successfully brought into flower in a specially designed glasshouse at Chatsworth, the estate of the Duke of Devonshire. It is said that Joseph Paxton who was the Duke's head gardener at the time, based the design of the glasshouse in which it was grown on the complex, but regular and structurally sound, system of veins on the underside of the leaf of the water lily (Plate 1). The design of this glasshouse was inspirational and was subsequently used as the basis for the designs for the Crystal Palace, built for the Great Exhibition of 1851.

\section{PROPAGATION}

In its natural habitat the Victoria water lily is a perennial plant that can survive for many years because of the uniform day length of approximately 12 hours in the tropics. Indeed, a plant may be kept for many years in the temperate regions with the aid of supplementary lighting. However, in higher latitudes the plants lose their condition when light levels drop in winter and it is therefore best treated as an annual and propagated from seed each year.

In late January $5 \mathrm{~cm}$ clay pots are filled with riddled loam. The pea sized seed is placed on top of the loam and half covered with chick grit; a quartz grit approximately

\footnotetext{
'Pat Clifford is a Senior Indoor Horticulturist at RBGE. Address: Royal Botanic Garden Edinburgh, 20a Inverleith Row, Edinburgh EH3 5LR. Email: p.clifford@rbge.org.uk
} 
$2 \mathrm{~mm}$ in diameter. At RBGE we have found that viability seems to drop quite drastically as the seed ages so it is always best to use the freshest seed available. The pots are then placed to a depth of $100 \mathrm{~mm}$ in water heated to $32^{\circ} \mathrm{C}$. At RBGE a 1000 litre tank situated in the tropical propagation area is used for the propagation of a number of tropical aquatic plants including this water lily. Germination usually occurs within 2-4 weeks and seedlings are potted on in to $10 \mathrm{~cm}$ pots when the second set of true leaves have developed. Plants are potted on as necessary until planting out in the final container in the display pond.

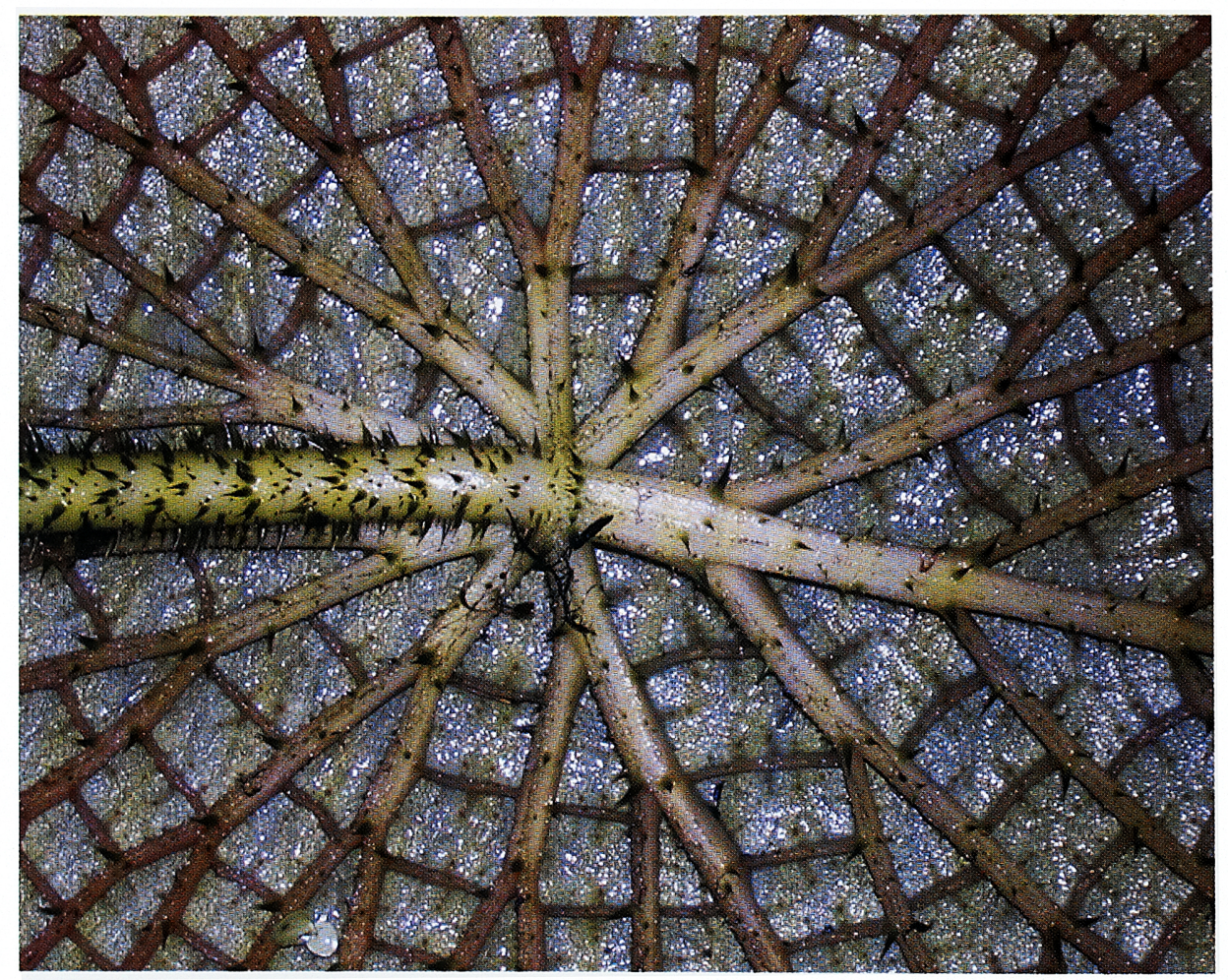

Plate 1. Underside of the leaf of Victoria amazonica.

\section{PLANTING OUT}

By the end of March the leaves on the young plants should be $300 \mathrm{~mm}$ across signalling the correct time to plant them in their final tubs. At RBGE the Victoria water lilies are grown in the 'People and Plants' house (formerly the Tropical Aquatic House) in the main range of public display houses. The pond in which they are grown holds 82,000 litre of water and has a surface area of $80 \mathrm{~m}^{2}$ which allows three plants to grow to full size (Plate 2). The water is kept at a constant $29^{\circ} \mathrm{C}$ and the air temperature in the glasshouse has a minimum day temperature of $24^{\circ} \mathrm{C}$ and a night minimum of $19^{\circ} \mathrm{C}$. However, in summer temperatures of up to $30^{\circ} \mathrm{C}$ during the day are common. 
Just before it is time to carry out the planting operation the pond is drained, last year's soil is emptied from the tubs and replaced by new, fresh loam. The loam is roughly chopped but not riddled. Care must be taken when sourcing the turf for the loam stack and the stack should have had at least 18 months to break down before use. There were disastrous results to the water lilies one year at RBGE when turf was donated from a bowling green. This was due to the residues of herbicides that had been sprayed on to the bowling green over the years.

The tubs in which mature plants are grown are $600 \mathrm{~mm}$ deep and $900 \mathrm{~mm}$ in diameter and, when in place, the top of the tubs sit $400 \mathrm{~mm}$ below the surface of the water. Once the tubs are filled with loam a $30 \mathrm{~mm}$ deep layer of coarse grit or gravel is placed on top to ensure that the loam does not float out of the tub when the pond is refilled.

The plants are moved from the propagation area to the display house in May and placed on the newly filled tubs. The pond is refilled and they are left for a week to acclimatise and to allow the petioles to lengthen. The purpose of this is that when they are planted in the tubs the leaves will sit flat on the surface of the water. When transplanting to the final growing place great care is required not to damage the fleshy root system. It is also essential that the plant is pushed firmly into the loam and that the gravel is swept back over the planting hole. This minimises the risk of damage by small nest burrowing fish such as Cichlids (Cichlidae) of which there are many in the pond.

Unlike most ponds that are used to display Victoria water lilies at RBGE we also manage to grow many other genera. These include many Nymphea hybrids, Nelumbo nucifera (Nelumbonaceae), Pistia stratiotes (Araceae), and Eichhornia crassipes (Pontaderiaceae). The theme of the glasshouse is to display plants which humans use and so rice, Oryza sativa (Graminae), sugar cane, Saccharum oficinarum (Graminae), and Cyperus papyrus (Cyperaceae) are also grown.

\section{GENERAL MAINTENANCE}

One of the main requirements of the Victoria water lilies is a feeding regime that provides them with plenty of nitrogen and to this end high nitrogen fertiliser balls are made at RBGE. A wheelbarrow of poor soil is taken, any soil will do providing that it is not too clayey or contains large stones. An inorganic fertiliser with an NPK ratio of 2:1:1 is added to the soil at a ratio of 1:3. Water is added until the mixture is sufficiently sticky to fashion in to balls approximately the size of an apple. The balls are left to dry and harden in a cool dry place.

Throughout the growing season the plants are fed every $7-10$ days, the technique being to insert three balls to a depth of $300 \mathrm{~mm}$ at the point where the roots terminate. Later in the season when the plant roots have filled the tubs the balls are pushed in wherever possible. At this depth the ball will break down effectively and the feed will percolate through the root system.

With such heavy feeding and intensifying light levels the plants put on a massive amount of growth in early summer. By mid June the plants are fully grown and the largest 
leaves can reach up to $2 \mathrm{~m}$ across. At this time the plants are at their most spectacular and the maintenance schedule 'moves up a gear'. Great care must be taken when working around the plants because of their spiny nature. The spines on the underside of the leaf can cause a very nasty wound. This is always more dangerous when working in standing water because of the possibility of Leptospirosis (Weills Disease) which is carried in rat urine. Twice per week a member of staff goes into the pond to remove the older leaves in order to make space for the new leaves. From a personal viewpoint I prefer to allow some of the surface of the water to show because it contrasts beautifully with the leaves and provides some great reflections of the glasshouse structure to visitors. In order to achieve this some of the smaller leaves have to be removed as well as the large ones. The alternative to this method of displaying the plants is not to remove the leaves and to allow the water surface to be completely covered with many leaves competing with their neighbours for maximum sunlight. This approach enables the visitor to see what a huge and impressive plant the Victoria water lily really is.

Although the Victoria water lilies are not susceptible to many pests or diseases there is a problem with one particular species of aphid early in the growing season. At RBGE the policy is to try and use biological control whenever possible and this is particularly important when dealing with ponds, which may or may not contain fish. The predatory midge Aphidoletes aphidomyza (Cecidomyiidae) is very effective indeed. A batch of 1000 pupae is released when the plants are planted out. This is repeated weekly for the next four weeks. The adult midges hatch almost immediately and fly off, laying eggs near the aphid colonies. The eggs hatch and the emerging larvae begin to feed on the aphids. They do this by biting the leg of the larvae and injecting a paralysing toxin. The larva then begins to suck the fluids from the aphid. Each larva can consume up to 100 aphids. The life cycle from egg to adult takes approximately 28 days depending on the temperature of the environment.

\section{FLOWERING AND POLLINATION}

The plants begin to produce large flower buds as early as June. At RBGE the buds produced in the first month are cut off to encourage the plant to put all its energy in to leaf production. The Victoria water lily is night flowering, which is a pity because the general public never see or smell the first night flowers.

Pollination is a complex procedure and in the wild the flowers rely on beetles to do the job for them. On the first night the bud opens producing a spectacular white flower. It is the size of a melon and gives off a heady scent which attracts the beetle. The temperature inside the flower is higher than that outside and the beetle crawls into the tent-like structure of petals. Inside this tent there is plenty of nectar and while the beetle is happily feasting the petals close around the insect and trap it within.

While the beetle is inside the flower begins to change. First it cools down and changes colour, initially to pink and then to purple. When the beetle first entered the flower it was receptive to pollen from another plant, but once it has changed colour it is no longer 


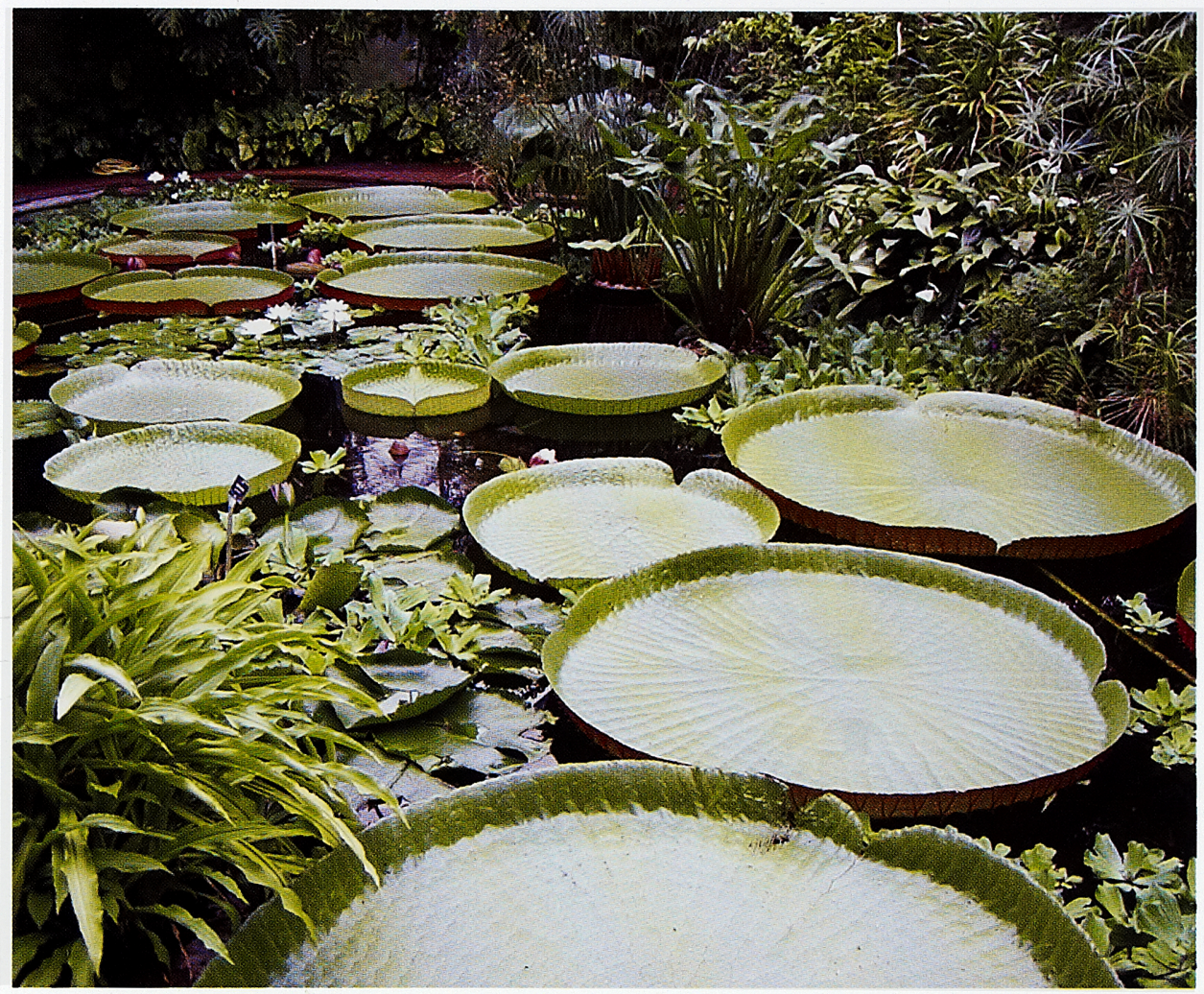

Plate 2. Victoria amazonica in the People and Plants display house.

receptive and cannot be pollinated. Instead its anthers ripen and release pollen of their own, coating the beetle in the fine powdery substance.

The following evening the flower opens and the pollen covered beetle flies off in search of another white flower where it will be rewarded with warmth and food. In order to enter the new flower the beetle will have to squeeze past the stigma thus pollinating the new flower (Bridgewater and Milliken, 2002).

At RBGE dedicated staff who return to the gardens in the late evening perform the function of the beetle. The pollen-laden anthers of a second night flower are gently snipped off and laid in a tray. They are taken over to the first night flower on another plant. The petals are carefully prised open until there is a big enough hole in the centre of the flower into which the anthers and pollen are deposited. A soft brush is used to move the pollen about inside the flower, thus dusting the stigma and pollinating the flower.

After pollination the seed pod begins to swell and within about six weeks it ruptures. To ensure that all the seeds are harvested a muslin bag is tied over the pod once it looks ripe. Up to 500 seeds can be produced per pod (Plate 3 ). These are covered in a glutinous white aril which needs to be washed off before the seeds are stored. They are kept in distilled water or wet sand at $14^{\circ} \mathrm{C}$ until it is time to sow them the following year. 


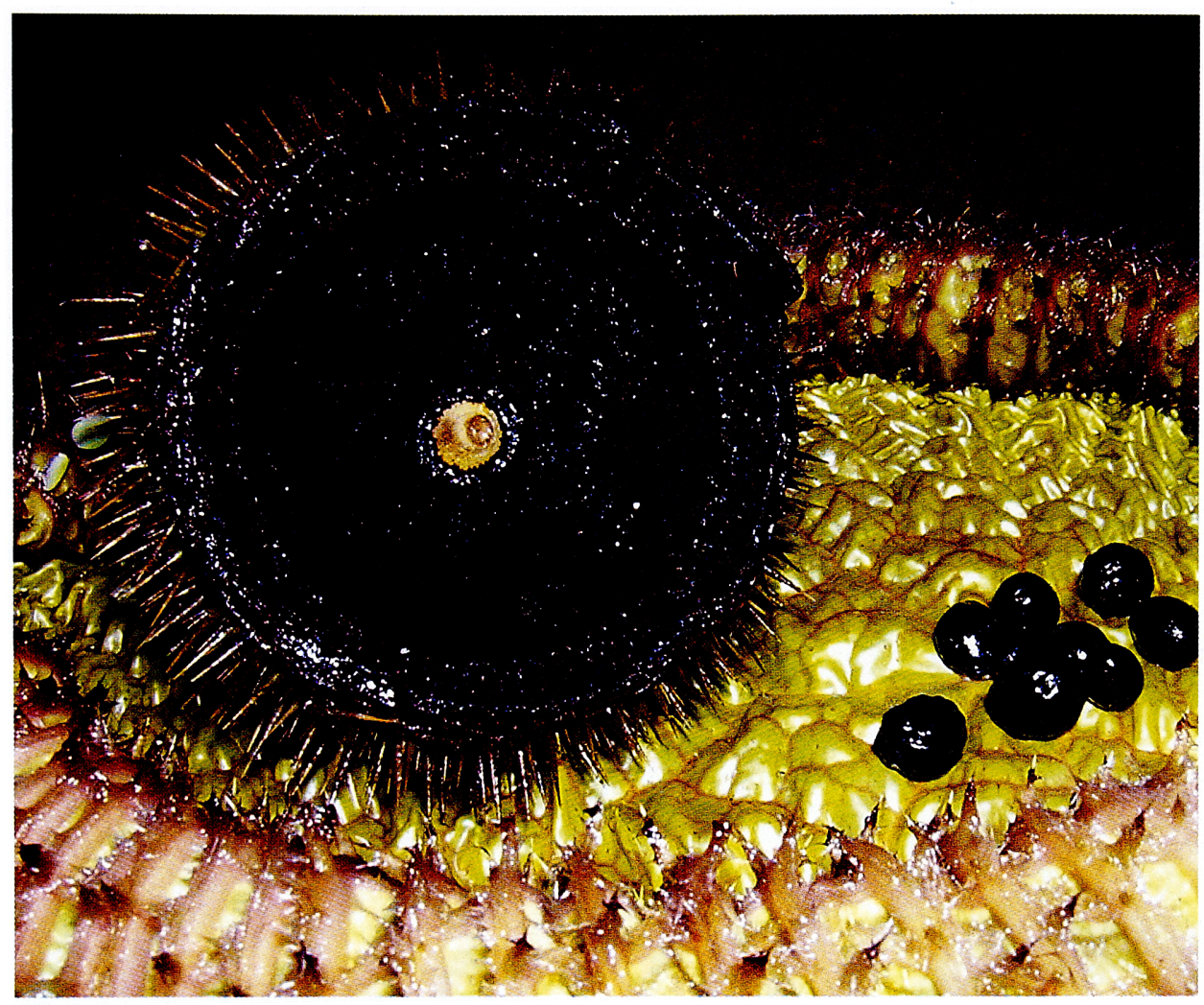

Plate 3. Victoria amazonica seedpod and seeds

The plants themselves give an excellent display from May until mid October when, due to the rapidly decreasing light levels the plants begin to deteriorate. The leaves begin to grow much smaller and softer, and eventually they rot off. When this happens the plant is removed and the pond returns to its more sedate winter state. Due to late planting in 2004 the Victoria water lilies in the RBGE pond lasted longer in to the winter and were not removed until the first week of December which was very unusual.

\section{VICTORIA CRUZIANA AND VICTORIA 'LONGWOOD HYBRID'}

$V$. cruziana, another species of water lily is displayed in the same pond as $V$. amazonica. This species is found primarily in Argentina, Paraguay and Uruguay. It has a more southerly distribution than $V$. amazonica and therefore does not require such high temperatures for seed germination or cultivation. At RBGE it is cultivated in the same way as V.amazonica and positively thrives on this treatment. Although the leaves do not grow to the same dimensions as $V$. amazonica they have a far more pronounced upturned lip which can measure $150 \mathrm{~mm}$.

The Longwood Hybrid water lily is also grown at RBGE when seed is available. This hybrid was developed in 1960 at Longwood Gardens in Pennsylvania, USA. The pollen 
was taken from a flower of $V$. amazonica and used to fertilise the flower of $V$. cruziana. The resulting seeds produced a spectacular plant that is now grown around the world.

The progeny of this cross could not have turned out better. It displays the best characteristics of both parents, these are the extraordinary size and deep red colour to the undersides of the leaf of $V$. amazonica, and the large lip and relative hardiness of $V$. cruziana. These characteristics combined with its hybrid vigour have bred a truly beautiful plant. In the near future it is hoped that all three of these plants will be grown in the same pond and that interpretation will be provided to bring the world of hybridisation to the general public. There is surely no better plant than the Victoria water lilies to tell this particular story.

\section{REFERENCES}

ANDERSON, E. (1965). Missouri Botanical Garden Bulletin Vol. LIII No. 5

BRIDGEWATER, S. and MILLIKEN, W. (2002). Unpublished Audio Tour Texts for RBGE Glasshouses.

KNOTTS, K. Victoria's History www.victoria-adventure.org/victoria/victoria_history [Accessed March 2005]

LINDLEY, J. (1837) A notice of Victoria regia, a new nymphaceous plant discovered by Mr. $R$ H Schomburgk in British Guayana. Shakspeare Press. London. 
